\title{
HUMAN PERCEPTION AND AESTHETICS OF FAÇADES
}

\author{
UDO DIETRICH \\ REAP Research Group, Hafen City University Hamburg, Germany
}

\begin{abstract}
The spherical eye delivers only in a very small angle range of $2^{\circ}$ (the fovea) a sharp vision. To generate a sharp image of the whole field of view, the eye scans with very quick movements (saccades) of 4 to $15^{\circ}$ from one point of foveal view to the next one, and the brain completes the intermediate ranges to the final impression. The process of analysing an object is much facilitated if it offers elements in density, size and distance that are in accordance with the scanning process of the saccades. The analysis of an object is especially easy and full of pleasure if the eye's saccades are guided over the whole object with a system of order like in a well-done composition of a painting or a façade. Then, we perceive the object harmonically and perhaps finally aesthetically. A fractal is a mathematical set that exhibits a repeating pattern displayed at every scale. They have the potential to guide the eye over the different diminutions. In literature, different, as well-composed, generally approved objects (like paintings), were analysed to determine their fractal dimension. It was found as being located in a small range that can hold as recommendation for future design processes. The paper deals with the transfer of those findings to façades. Here, two typologies were created, one façade rich and one poor in elements, their fractal dimensions were determined. As a result, the façade rich in elements fits well with the range that is preferred by the human eye but the poor one does not; it does not offer enough elements for the saccades to facilitate the process of analysing. A recommendation can be derived for the size, number and distance of elements in façades for different viewing distances to support the eye in the perception process. A fractal character in the arrangement of these elements would further encourage a joyful view. Keywords: visual perception, human eye, foveal view, saccades, fractals, fractal behaviour of real objects, perception of façades, number, distance and size of elements in well appreciated façades.
\end{abstract}

\section{INTRODUCTION}

This section delivers a very short and reduced overview to the perception of the human eye. An extended version with more detailed explanation can be found in Dietrich [1].

The human eye is on optical apparatus with one lens; the receiver is on the backside of a sphere. For that reason, a sharp vision is possible only in a very small range of 1 to $2^{\circ}$. Outside of this foveal view the vision becomes more and more blurred (Fig. 1).

To get more information, the eye scans with little unconscious movements (saccades) the area around the main direction of view. These saccades take place each 0.2 to $0.6 \mathrm{~s}$ and in an angle of 4 to $15^{\circ}$ from one saccade to the next one [3]. That delivers an image with few sharp spots. The rest of the generation of a fully sharp image is done by the brain; it complements the missing information to a sharp image (Fig. 2).

The pattern of saccades around the direction of view might be haphazardly if we do not expect something from the observed object. But in most cases the saccades are guided. That guidance can be caused by the brain if we are looking for certain information (Figs 3 and 4).

Vice versa, the object itself can guide the saccades if we want to explore the object in general, like a painting or a façade (Fig. 5). To facilitate the perception it is optimal, if there, where the next saccade is striking on the object, there is a distinguished element in the object. If saccades can, driven by that attraction of single elements, run smoothly over the object, the object itself is perceived as balanced, interesting, dynamic, and aesthetical. 


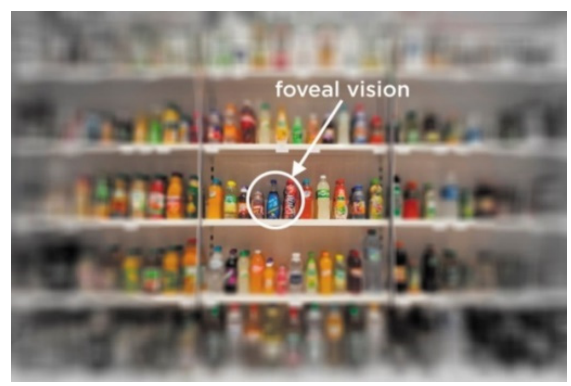

Figure 1: The foveal vision of the human eye without further completion of the brain (the image would be supplementary bottom-up). (Source: Eye Tracking [2].)

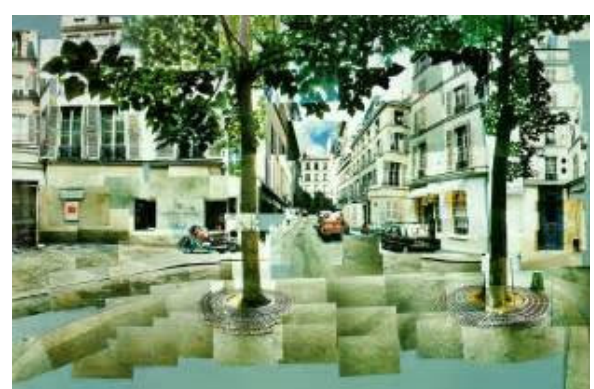

(a)

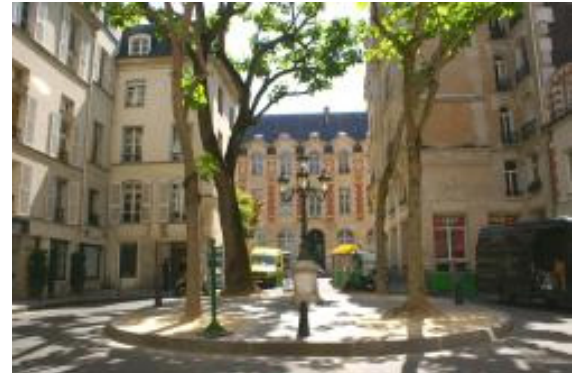

(b)

Figure 2: Illustration of the interaction between the human eye with saccades and the brain. A patchwork of information is taken by the eye's saccades, like (a) The work of David Hockney, Place Furstenberg Paris, 1985 (Source: Hockney, 1985 [4]), and the final smoothing by the brain, like in (b) The photography of the same place (Source: Tripadvisor [5].)

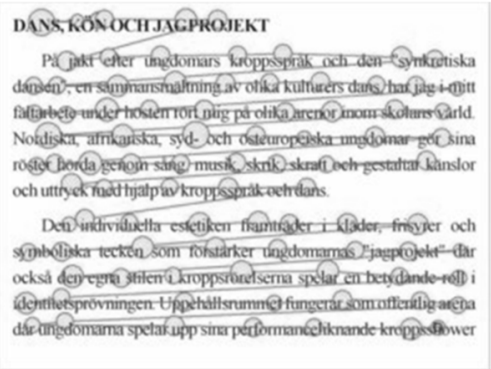

(a)
For taht rosaen we can raed and udnernsntad qiute esay a txet wehre olny the fsrit and the lsat letetr are in the cerocrt oedrr.

Figure 3: Reading a text. (a) Illustration of the saccades jumping from word to word, mostly forwards, sometimes backwards. The brain completes the fragmented information to the full text based on experience and knowledge of the words (Source: Bielefeld University [6]); and (b) Text where only the first and the last letter are in the correct order. We can read such text without big problems - the brain complements the missing information. 


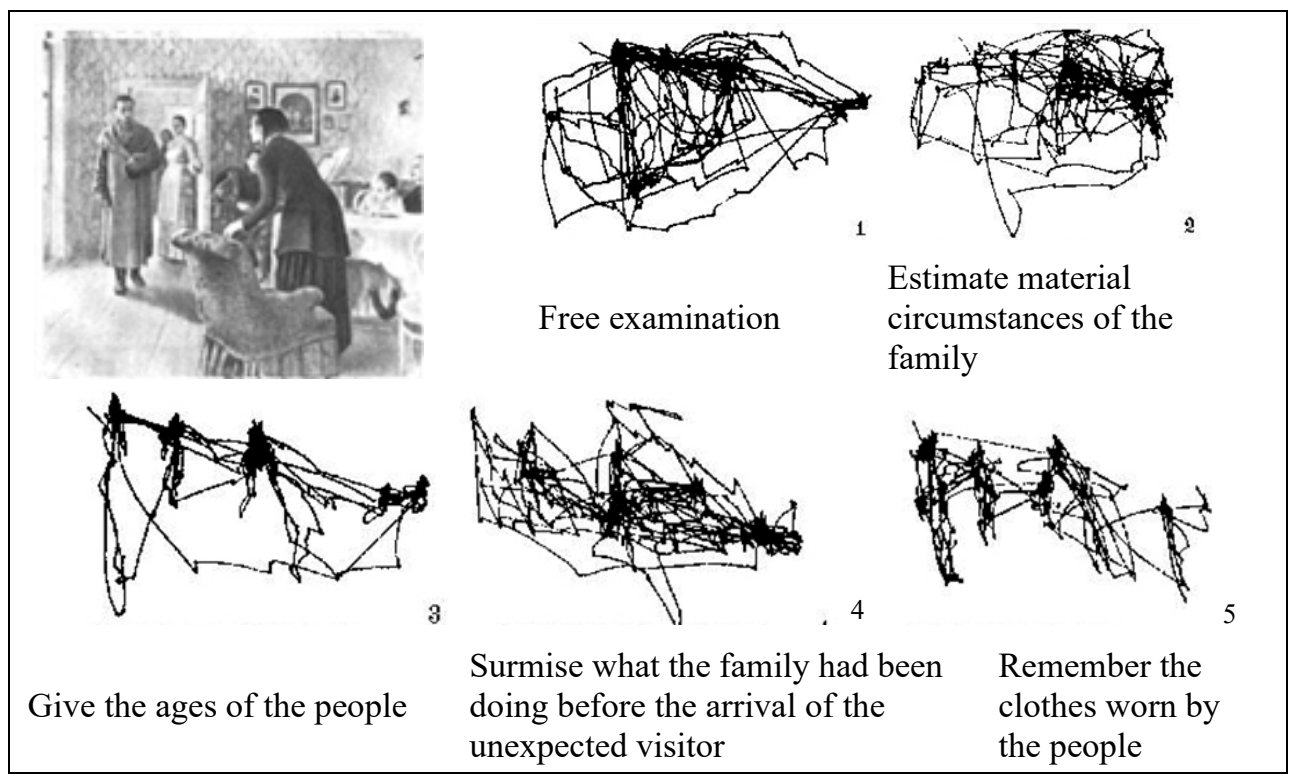

Figure 4: Illustration of brain-controlled saccades if the observation is related to an intellectual task (pictures 2-5); picture 1 shows the free examination. (Source: The Vision of Alfred Yarbus [7].)

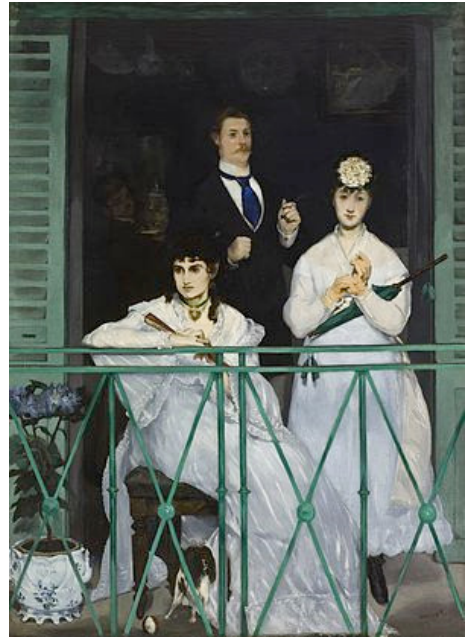

(a)

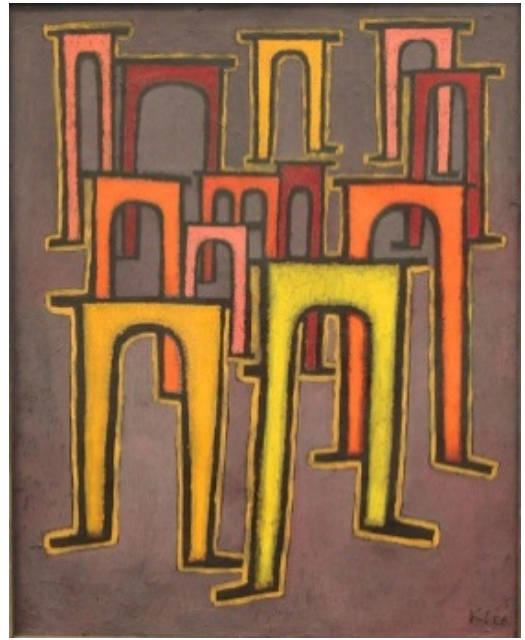

(b)

Figure 5: Examples of paintings that are well accepted as highly aesthetical, independent of their style as more realistic or even abstract. (a) Edouard Manet, The Balcony, 1868 (Source: Musee d'Orsay [8]); and (b) Paul Klee, Revolution of the Viaduct, 1937 (Source: Hamburger Kunsthalle [9].) 


\section{FRACTALS}

\subsection{Mathematical fractals}

A fractal is a mathematical set that exhibits a repeating pattern displayed at every scale. Ideal mathematical fractals show the same pattern at each scale, from the biggest to the smallest and also infinitive ones (Fig. 6).

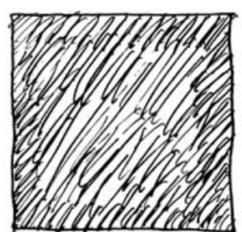

0

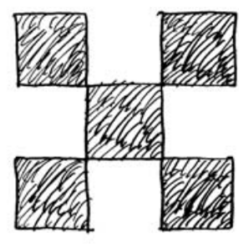

1

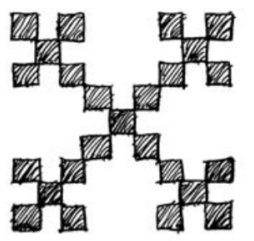

2

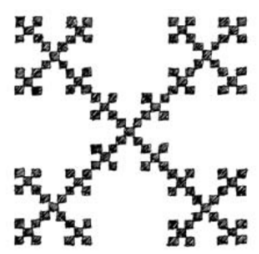

3

Figure 6: Example for a mathematical fractal. It is composed by partitions that could be continued to infinity. (Source: Salingaros [10].)

Fractals look very interesting; the human eye can observe the elements in different scales easily and with high pleasure. Fractals have an aesthetical quality.

\subsection{Natural fractals}

Fractals in the real world have been identified in many fields. Such natural fractals occur in nature (cauliflower, snail shell, peacock, fern, trees etc., Fig. 7) as well as in architecture (façades, shape of roofs) or urban scale (street grids). Their scaling cannot be infinite like with mathematical fractals, the magnification as well as the diminution must have an end at a certain scale. The question arises how many cycles in diminution are necessary that the eye perceives it already as a fractal. Salingaros [10] and Lorenz [14] state that in minimum three partitions are necessary to reach that target.
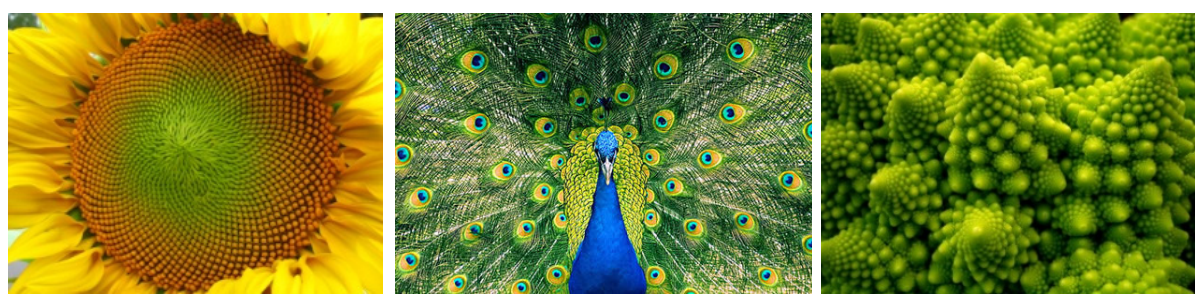

Figure 7: Examples for natural fractals. They are composed by a finite number of partitions. (Source: Imgur [11], FanPop [12], 3.bp.blogspot.com [13].)

\subsection{Fractal dimension}

\subsubsection{Mathematical fractals}

Each diminution reduces the typical length of the structure from 1 down to a value $\varepsilon$ between 0 and 1. In Fig. 6 it is each time $\varepsilon=1 / 3$. By each diminution a typical number $\mathrm{N}$ of new 
elements is created, in Fig. 6 each time $\mathrm{N}=5$. For mathematical fractals the exact definition of $\mathrm{D}$ is by calculating the limit of the scaling factor $\varepsilon$ to zero, eqn (1).

$$
\mathrm{D}=\lim _{(\varepsilon \rightarrow 0)}(-\log (\mathrm{N}) / \log (\varepsilon)) .
$$

For self-similar fractals (for identical $\varepsilon, \mathrm{N}$ is always identical too), eqn (1) can be simplified:

$$
\mathrm{D}=-\log (\mathrm{N}) / \log (\varepsilon) \text {. }
$$

In Fig. 6 , there are $\varepsilon=1 / 3$ and $\mathrm{N}=5$; the calculation ends with $\mathrm{D}=1.46$. For two-dimensional objects, D is always a value between 1 and 2 (Fig. 8).

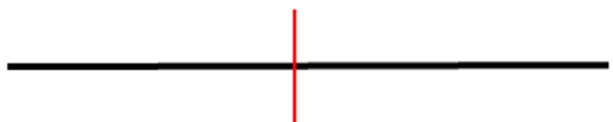

(a)

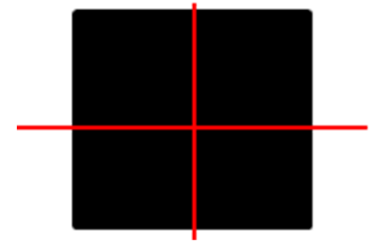

(b)

Figure 8: A one- and a two-dimensional object that is partitioned 50-50 in each dimension $(\varepsilon=1 / 2)$. The resulting fractal dimension is $\mathrm{D}=1$ for the one- and $\mathrm{D}=2$ for the two-dimensional object. (a) $\varepsilon=1 / 2, \mathrm{~N}=2, \mathrm{D}=1$; (b) $\varepsilon=1 / 2, \mathrm{~N}=4, \mathrm{D}=2$.

If we split a line, we create two new elements, the fractal dimension is $D=1$. If we separate a black square by two central lines $(\varepsilon=1 / 2)$ into 4 squares the fractal dimension is $\mathrm{D}=2$. An object that fills with its elements nearly the whole area will have a dimension near to two; an object that is composed only by a few singular lines will have a dimension near to one.

In general, it can also be said that so smaller D is so less new elements are created with a new diminution.

\subsubsection{Natural fractals}

In spite of the fact that an object is perceived by the eye as fractal if there are in minimum three partitions, with only three partitions it is not possible to calculate the fractal dimension in the mathematical way according to eqns (1) or (2).

To generate nevertheless a fractal dimension for natural fractals there are different possibilities described in literature, particularly the log-log plot and the loop-wise calculation.

The $\log -\log$ plot is a graph where the $y$-axis $\operatorname{shows} \log (\mathrm{N})$ and the $\mathrm{x}$-axis $\log (1 / \varepsilon)$. If there is for natural structures a (partly) fractal behaviour, then the points formed by different partitions should form a straight line. Their slope corresponds by definition to the fractal dimension D. As an anticipate part of the results of this paper, Fig. 9 shows a log-log plot for two different façades, one is rich in details, the other one poor (see Section 2.4 for explanation). It is possible to create seven diminutions; the corresponding points form a (nearly) straight line. Their fractal dimension can be determined as $\mathrm{D}=1.68$ for the rich and 1.21 for the poor façade. 


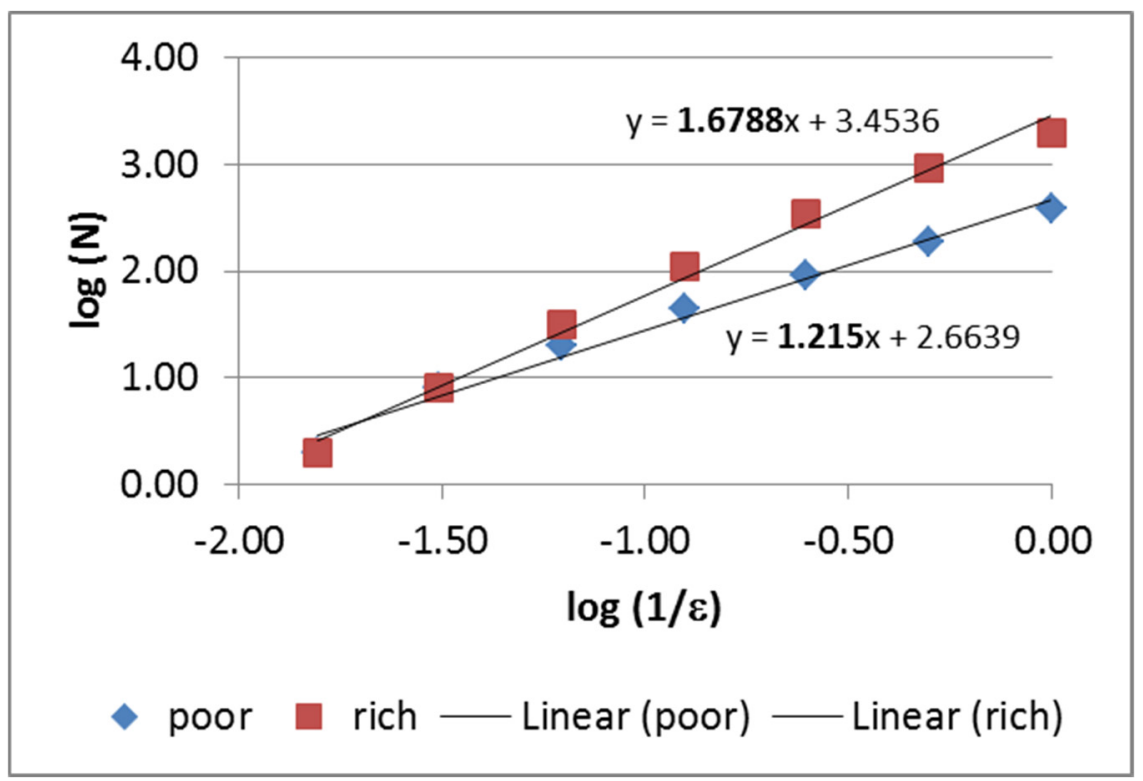

Figure 9: A log-log plot showing the fractal behaviour of the elements of building's façades. The slope of the regression line corresponds to the fractal dimension that is remarkably higher for a façade that is rich in details $(\mathrm{D}=1.68$ in comparison to a poor façade $\mathrm{D}=1.21$, see Section 2.4).

The log-log plot generates a value for $\mathrm{D}$ as general information. But it hides the behaviour of natural fractals. They start as rich in elements at a big scale (and thus values of D near to two). With each diminution the richness in elements decreases (and with it, D) until the natural fractal is exhausted and the structure becomes a linear one (and thus values of D near to one). This behaviour could be visualized with a step by step calculation for each diminution. D can be calculated for each loop by Lorenz [14], see Section 2.4 for examples:

$$
\mathrm{D}=\log (\mathrm{N} 2 / \mathrm{N} 1) / \log (\varepsilon 1 / \varepsilon 2) .
$$

\subsection{The box counting method}

An often used, possibility to count the number of elements especially for natural objects with only partly fractal character is the box counting method.

To investigate a façade its structure and elements are replaced by a linear drawing. In the second step a grid is created that covers the whole façade, the dimension of the grid cells is $\varepsilon 1$. The number of grid cells that are "filled" with a part of the linear drawing is counted (N1). In the next step the size of the grid cells is scaled down by a factor of $\varepsilon 2$. The number of filled grid cells is counted again (N2). The fractal dimension for the whole loop can be calculated according to eqn 3 .

Fig. 10 shows exemplarily the determination of the fractal dimension with box counting method for a loop-wise partition of fictive façades that are rich and poor in elements. 


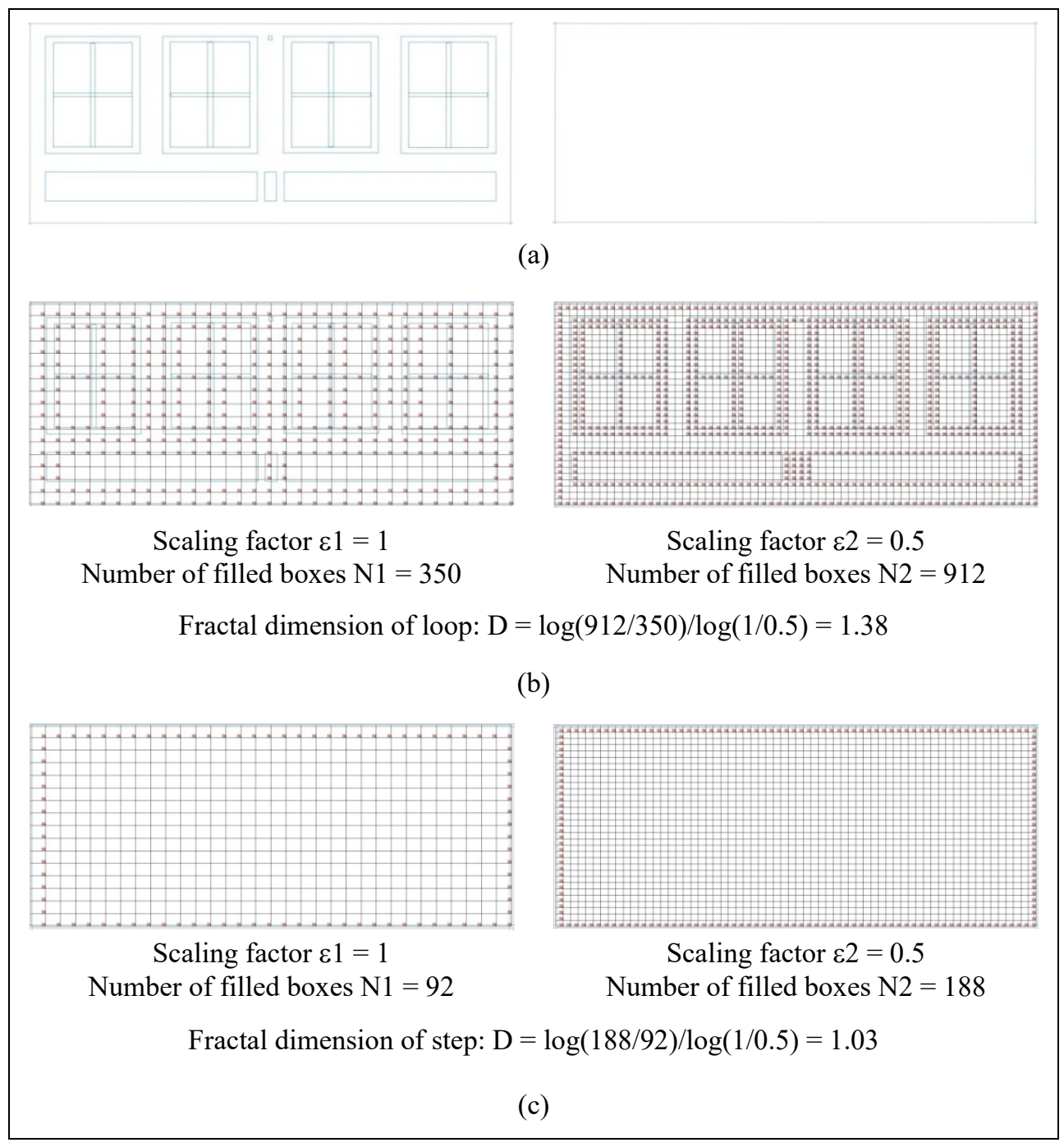

Figure 10: Determination of the fractal dimension for a partition loop. As an example, two façades were chosen, one rich in elements, the other one poor in elements. (a) Linear drawing of rich (left) and poor (right) façade; (b) and (c) Grid for box counting method; filled cells are marked, all others are empty; (b) Rich façade; (c) Poor façade.

\section{FRACTAL DIMENSIONS THAT ARE PREFERRED BY THE HUMAN EYE}

\subsection{Stress reduction}

Looking on a fractal structure that reduces stress, the most preferred ones have a D between 1.3 and $1.5[15]$. 


\subsection{Well-appreciated paintings}

Salingaros [10] reports that "Alexandra Forsythe and collaborators, while supporting the healing value of fractal surroundings, propose that the preferred fractal dimension is much higher, between 1.6 and 1.9. As evidence, they present the fractal dimension of well-known paintings, such as Botticelli's "The Birth of Venus" $D=1.86$, Monet's "Water Lilies" $D=1.78$, and van Gogh's "Sunflowers" $D=1.76$. Elsewhere, Ali Lavine computed Hokusai's "Great Wave off Kanagawa" to have $D=1.73$. These numbers, if independently confirmed, would of course require reconciliation with experimental data". Fig. 11 shows Botticelli's "The Birth of Venus" as reference.

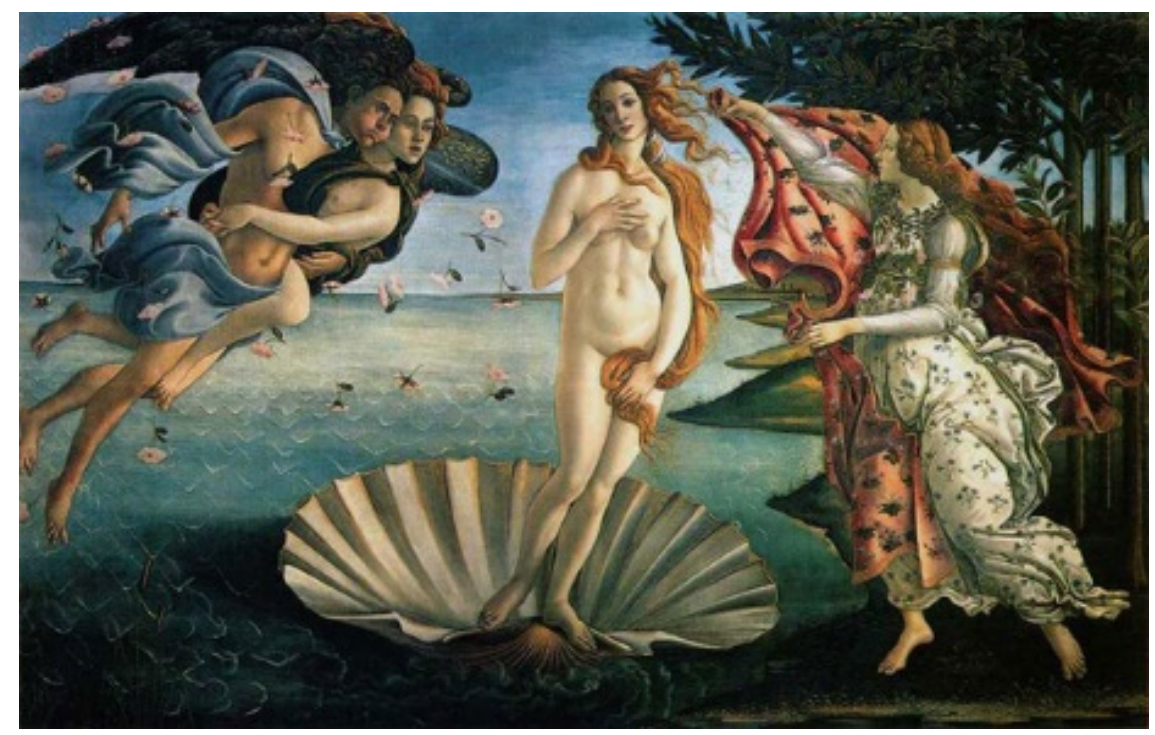

Figure 11: Sandro Botticelli, The Birth of Venus (1482-85), Florence. Fractal dimension $\mathrm{D}=1.86$. (Source: Le Gallerie Degli Uffizi [16].)

To determine the fractal dimension (e.g. with box counting method) the painting has to be transformed into a linear drawing showing all the elements that are in it. But this process is very subjective. What is an element and what not? Does each single trace of a hair of the brush that is painting the sky form an element or is the blue sky one single element as a whole? If there is a difference not by shape but by colour (contrast) - when are we allowed to define it as a new element?

Thus, the results also have a subjective component. But anyway, because different authors came to similar results there should be objective information in it.

\subsection{Pattern of saccades as a fractal}

Also, the pattern that is formed by the saccadic movement of the eye during the observation of an object is a fractal.

To avoid the subjective character of transferring a colour painting into black and white information it was a very good idea to choose the also well-appreciated paintings from Jackson Pollock for the investigation (Fig. 12, black). 
The fractal dimension of Pollock's paintings varies in a wide range between 1.11 and 1.89. The eye-tracks that are generated by observing these paintings are recorded and analysed (Fig. 12, red). Surprisingly their fractal dimension is all the times at values of about 1.5 independent of the fractal dimension of the observed object [17].

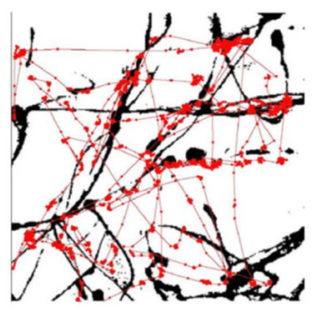

(a)

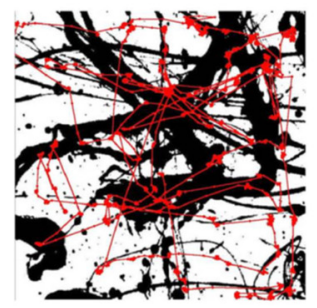

(b)

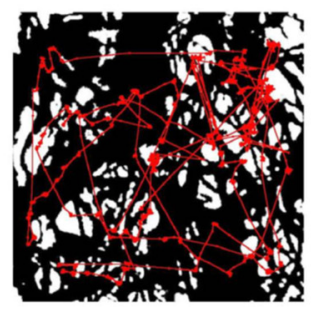

(c)

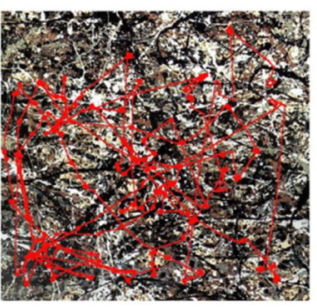

(d)

Figure 12: Sections of paintings of Jackson Pollock and their fractal dimensions which have (a) $\mathrm{D}=1.11$; (b) $\mathrm{D}=1.66$; and (c) $\mathrm{D}=1.89$. The last pattern (d) is a coloured composite of four $\mathrm{D}=1.6$ patterns. The eye-tracks are overlaid (red) on the observed fractal patterns; they also form fractals [17].

That means that, if the eye is not guided to follow a prescribed sequence of what to explore like in a text reading process, it follows all the times a fixed structure in observation process. Many mini-saccades of only a few degrees explore the nearer surrounding of a selected region of the object, a few mid-range saccades to explore the neighbourhood and some rare big saccades to skip to the next range.

Vice versa objects with a fractal structure and a dimension of 1.5 are most easily to observe and thus perceived as most aesthetical or less stress producing.

It can be summarized that the most preferred fractal dimension is in the range between 1.3-1.8 (stress reduction 1.3-1.5), better 1.5-1.9 (paintings).

\section{PERCEPTION OF FAÇADES - INVESTIGATION METHOD AND RESULTS}

\subsection{Choice of representative façades}

Façades are no mathematical objects. Even if they are fractal, the number of diminutions is limited by the size of the building on one side and the resolution of the human eye on the other one.

In literature, façades are replaced by a drawing of lines for the determination of their fractal dimension (e.g. with box counting method). Like already discussed in Section 3.2 for paintings, the decision which part of the façade is an element creating a line in that drawing is very subjective and would probably end with different results for different persons creating this drawing. Also, in the contrary to paintings, the situation for façades is a bit different. There are no really general well-appreciated examples of aesthetic, nice façades. Experts and lay persons as well as the "vote by feet" do not agree clearly in examples that could be used for investigations.

For all those reasons, real façades are not regarded in that paper, but images that are representative for two opposite extremes are chosen, one is rich in elements, the other one poor. Most of the façades lay between both but there also real façades that correspond to the extremes. Fig. 13 shows also real representatives for both. 


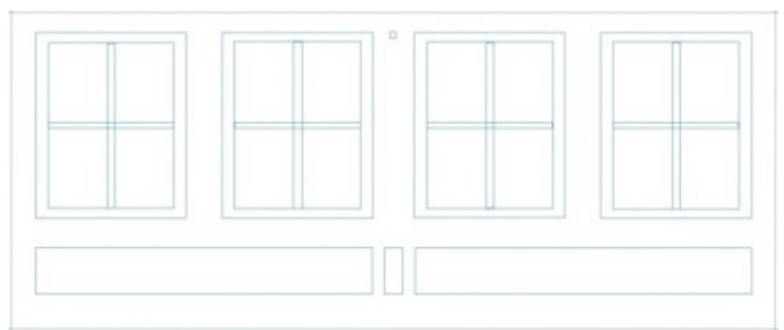

(a)

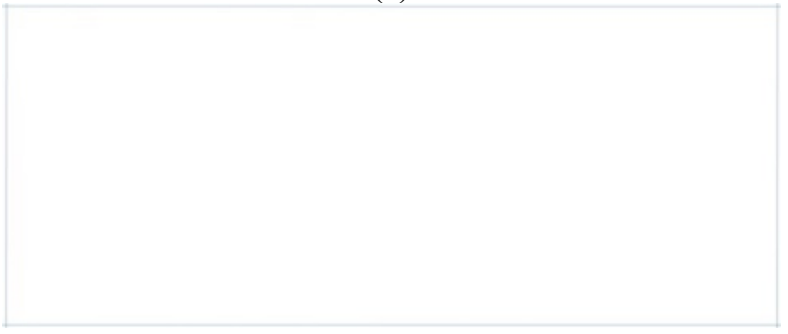

(b)

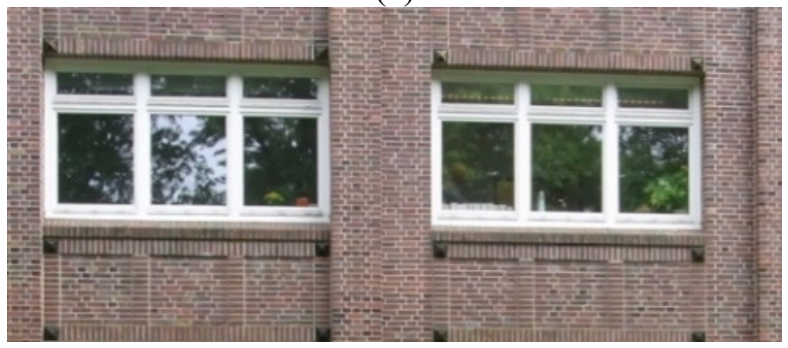

(c)

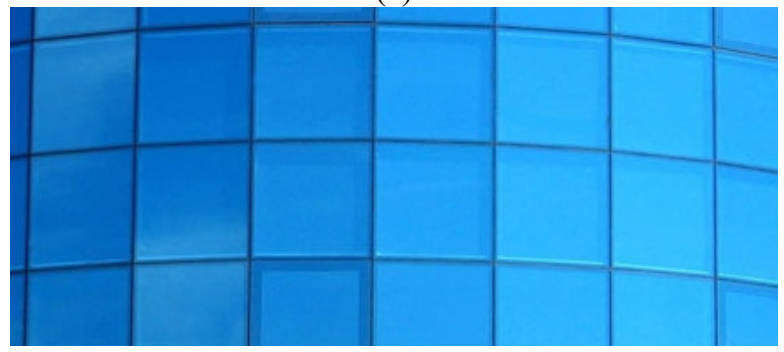

(d)

Figure 13: Top - fictive linear drawings as representatives for façades that are (a) Rich; and (b) Poor in elements. Bottom - photographs of real façades that correspond to these representatives and are (c) Rich in elements (own picture); and (d) Poor in elements. (Source: Notre Dame de Paris [19].)

A fractal is described by a yes and no, yes means there is an element and no means there is an empty area. How can that mathematical rule be adapted to façades? What is an "element" and what is an "empty area" here? A façade is composed by a number of constructive or decorative elements and shapes that can be differentiated by the human's eye by contrast in material, colour or brightness. 
These elements can be two AND also three dimensional what is not foreseen in fractals theory, they are 2D OR 3D. Further, a façade in the sun shows sharp shadows forming (moving!) lines of high contrast but there is no real element! A sum of smaller elements could be arranged in a way that they form an element that is perceived clearly as a bigger element without being really a new element. Behind transparent parts of façades objects of the interior of the building (stairs, furniture etc.) might be visible as supplementary elements that can be counted or not.

\subsection{Viewing distance and foveal view}

The whole horizontal field of view of the human eyes spans about $110^{\circ}$, the foveal (sharp) view in it spans only $2^{\circ}$. That corresponds to typical views on elements of façades for different viewing distances (Fig. 14). In a town the most typical viewing distances are about $20 \mathrm{~m}$ for the street width (= watching the opposite façades), $10 \mathrm{~m}$ for the middle of the street, 2 to $3 \mathrm{~m}$ for a position on the sidewalk. Seen from these distances, façades should be perceived as interesting, dynamic, and aesthetic.

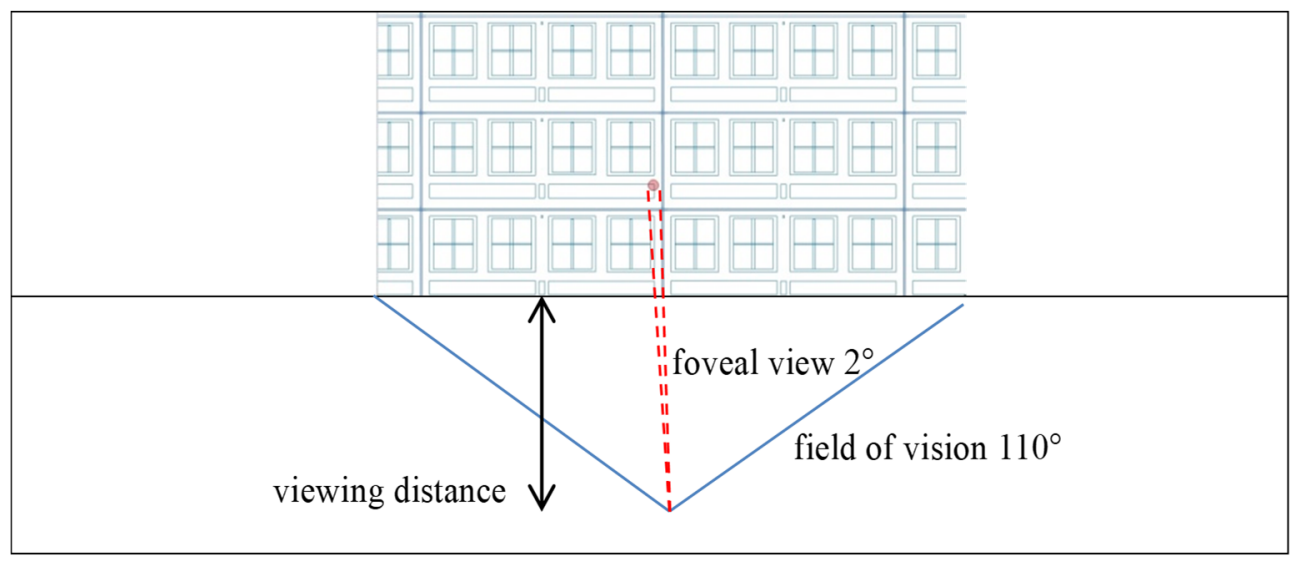

Figure 14: The view on a façade out of an exemplarily distance of $4.6 \mathrm{~m}$ (see Table 1). The corresponding field of vision with $110^{\circ}(13.1 \mathrm{~m}$ façade) and the foveal view of $2^{\circ}$ only (element of $0.16 \mathrm{~m}$ ) are added.

Following the findings in Section 3 that is the case, if there, where the view strikes on the façade, a distinct element in the size of the foveal view can be recognized. Table 1 gives an overview to the extension of such elements in dependence of the viewing distance. The resulting size of elements for the common viewing distances ranges from 1 to $2 \mathrm{~m}$ (window size) for the view from far, from 50 to $100 \mathrm{~cm}$ for viewing a façade on the opposite of a street down to 5 to $10 \mathrm{~cm}$ for the view from the sidewalk.

\subsection{Results - the fractal dimensions of the chosen representative façades}

But much better in information is the description loop-wise (see Section 2.3.2). For the same façades the box-counting method was used over 7 loops (see Fig. 10). The diminution corresponds to a decreasing viewing distance according to Table 1. 
Table 1: The diameter of foveal (sharp) view and the width of the field of vision for different viewing distances (see Fig. 14).

\begin{tabular}{|c|c|c|}
\hline $\begin{array}{c}\text { Viewing distance } \\
(\mathrm{m})\end{array}$ & $\begin{array}{c}\text { Diameter of foveal view } \\
(\mathrm{m})\end{array}$ & $\begin{array}{c}\text { Width field of vision } \\
(\mathrm{m})\end{array}$ \\
\hline 73.3 & 2.56 & 209.5 \\
\hline 36.7 & 1.28 & 104.7 \\
\hline 18.3 & 0.64 & 52.4 \\
\hline 9.2 & 0.32 & 26.2 \\
\hline 4.6 & 0.16 & 13.1 \\
\hline 2.3 & 0.08 & 6.5 \\
\hline 1.1 & 0.04 & 3.3 \\
\hline
\end{tabular}

Fig. 15 shows the results, supplementary a rectangle is included showing the most common viewing distances and the by the human's eye preferred fractal dimensions. It can be seen that for the façade rich in elements the points that correspond to common viewing distances lay inside this rectangle (easiest perception for the human eye) but for the façade poor in elements not. The rich façade can offer an element for fixation for the foveal view at any viewing distance, the poor one is reduced too quickly to an only linear structure with fractal dimension near to one.

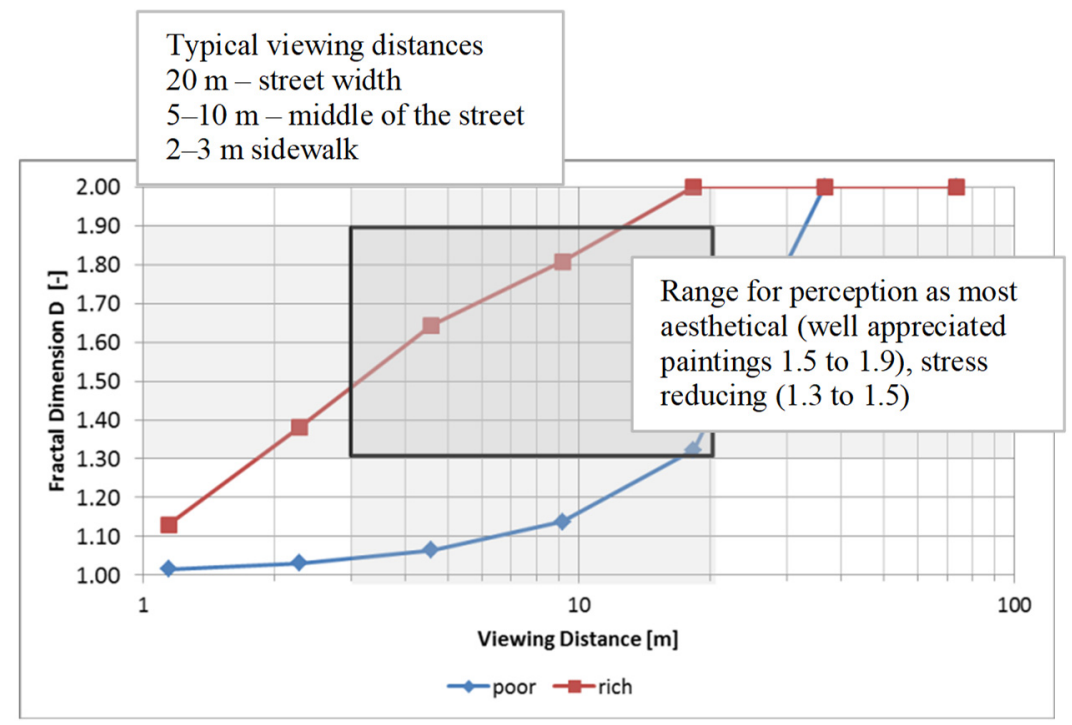

Figure 15: The diagram shows the loop-wise determined fractal dimension of the two chosen fictive façades, one is rich, the other poor in elements. Each diminution corresponds to a viewing distance; it is shown in the graph.

The black rectangle marks common viewing distances as well as the by the human eye preferred fractal dimensions. The corresponding points of the loops determining the fractal dimension should lay in that rectangle. 
The fictive façades representing typologies rich and poor in elements shown in Fig. 10 were analysed. With the log-log plot (Fig. 9) were found $\mathrm{D}=1.68$ for the rich and $\mathrm{D}=1.21$ for the poor façade.

\subsection{Saccades on façades - interpretation of results}

The results from Fig. 15 can be interpreted also differently. Fig. 16 shows the view on both fictive façades. The red point marks the first saccade. It hits an element, delivering information to read and understand the façade. The next saccade(s) occur in a range of 4 to $15^{\circ}$ around the first one. For the façade rich in elements each of the following saccades hits also an (other) element. But not for the façade poor in elements, the neighbouring saccades go into emptiness - it is difficult for the eye to scan, to "understand" the façade because it gives no answer.

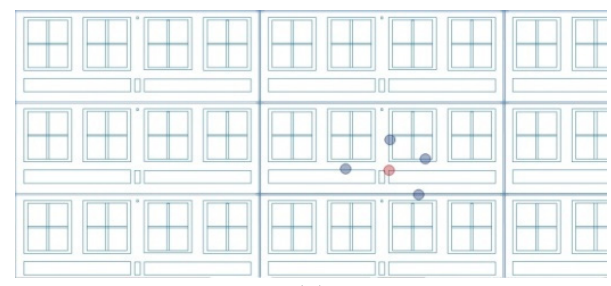

(a)

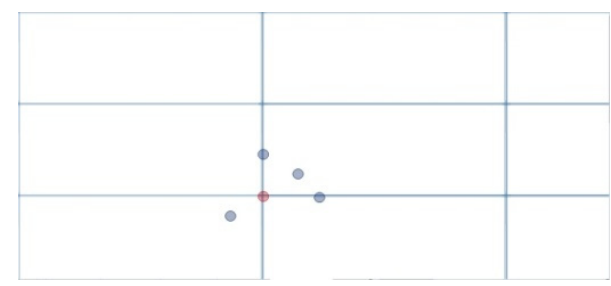

(b)

Figure 16: The view on the two fictive façades, (a) Rich; and (b) Poor in elements, seen from a distance of $4.6 \mathrm{~m}$. The red circle presents the foveal view of $2^{\circ}$ of the first saccade striking on the façade. The next possible saccades would lie in a range of 4 to $15^{\circ}$ and are marked with blue circles. The rich façade offers always an element to fix - easy to scan, the poor façade not.

\subsection{A comment to the significance of the box-counting and fractal behaviour}

The box counting method and its loop-wise analysis (like in Fig. 15) deliver valuable information. It has to be noted, that it is a measure for the richness in elements but NOT for fractal behaviour. Even if a non-fractal structure is investigated there will be a result and a "fractal dimension". Non fractal structures could be:

- A grid (like the grid that is used for counting) is rich in elements, but not at all fractal! All elements are of the same size.

- A totally chaotic structure that can't be generated with a partitioning process with fractal character (each diminution creates a number of new elements).

Thus, a good result in box counting must not mean that the structure is really fractal. The box counting method shows much more if the object is in the investigated range of diminution rich in elements or not. But, especially for natural objects it does not proof that the structure is fractal. A structure is only fractal if the box counting method would deliver constant values for $\mathrm{D}$ for a higher number of diminutions. A fractal structure has a self-similarity; it offers details of different sizes at different scales that are linked with each other. This decision fractal or not must also be taken outside of box-counting! 


\section{DESIGNING FRACTAL}

\subsection{Self-similarity}

On closer observation, taking into account the geometry of fractals, three main types of architectural compositions can be differentiated - with many nuances in between [14] (Fig. 17 shows examples and more explanation):

- Façades rich in elements but with unstructured composition, leading to chaos and confusion.

- Façades poor in elements, not inviting to watch at, boring.

Façades rich in elements and with structured/fractal composition, leading to easy understanding and a pleasure to watch.

\begin{tabular}{|l|l|l|}
\hline $\begin{array}{l}\text { Unstructured façades which } \\
\text { offer disconnected details } \\
\text { of different sizes on } \\
\text { different scales and } \\
\text { therefore lead to confusion } \\
\text { - the first extreme. }\end{array}$ & $\begin{array}{l}\text { Any lack of visual depth } \\
\text { leads to uninteresting, if not } \\
\text { boring buildings - the second } \\
\text { extreme. }\end{array}$ & $\begin{array}{l}\text { Those buildings that } \\
\text { offer self-similarity } \\
\text { belong to the third group } \\
\text { in between, offering } \\
\text { details of different sizes } \\
\text { on different scales linked } \\
\text { with each other. }\end{array}$ \\
\hline $\begin{array}{l}\text { More or less rich in } \\
\text { elements but chaotic, not } \\
\text { fractal }\end{array}$ & $\begin{array}{l}\text { Poor in elements and not } \\
\text { fractal }\end{array}$ & $\begin{array}{l}\text { Rich in elements and } \\
\text { fractal }\end{array}$ \\
\hline $\begin{array}{l}\text { Saccades find an element to } \\
\text { fix from all distances but } \\
\text { saccades are not guided to } \\
\text { scan the façade easily. }\end{array}$ & $\begin{array}{l}\text { Saccades do not find an } \\
\text { element to fix especially } \\
\text { from shorter distances (street } \\
\text { width, sidewalk) - the eye is } \\
\text { guided into emptiness. }\end{array}$ & $\begin{array}{l}\text { Saccades find an element } \\
\text { to fix from all distances } \\
\text { and saccades are guided } \\
\text { to scan the façade easily. }\end{array}$ \\
\hline \multicolumn{1}{|c|}{ (a) }
\end{tabular}

Figure 17: Examples for three extreme, opposite main types of façades, a real façade lies inside of the triangle that they form. (a) Rich in elements but chaotic, non-fractal; (b) Poor in elements and not fractal; (c) Rich in elements and fractal (all pictures by author). Further comments to their fractal character and the corresponding potential to observe them with the human's eye with pleasure are added in text. 
The last line in Fig. 17 shows the consequences for the endeavour of the eye to scan and to understand the façade. The poor façade does not offer enough (small) elements to fix for saccades and can't guide the eye in that process. The chaotic but rich façade offers elements to fix but does not guide the eye because of the lack of the "higher", fractal structure. Only the fractal façade serves the eye for fixations and guidance to explore the façade.

\subsection{Frequency rule}

This paper lists arguments that a façade is easy to read and understand and a pleasure to watch if each saccade striking on it meets a distinct element - and that from all common viewing distances. What would that mean for the frequency with which objects of different sizes should exist in a façade? Such a calculation can be based on the assumptions that (a) the foveal view is $2^{\circ}$, (b) the size of an element corresponds to certain viewing differences (Table 1) and (c) saccades have an average of $12^{\circ}$ and should find in that distance the next element.

As another result of this paper the correlation between the size of the elements and their number per $\mathrm{m}^{2}$ façade and could be generated (Fig. 18). The necessary number of elements increases exponentially with their decreasing size. A façade should show few determining elements of big size ( $1 \mathrm{~m}$ and bigger), a medium number of middle-sized elements (around $50 \mathrm{~cm}$ ) and plenty of smaller elements.

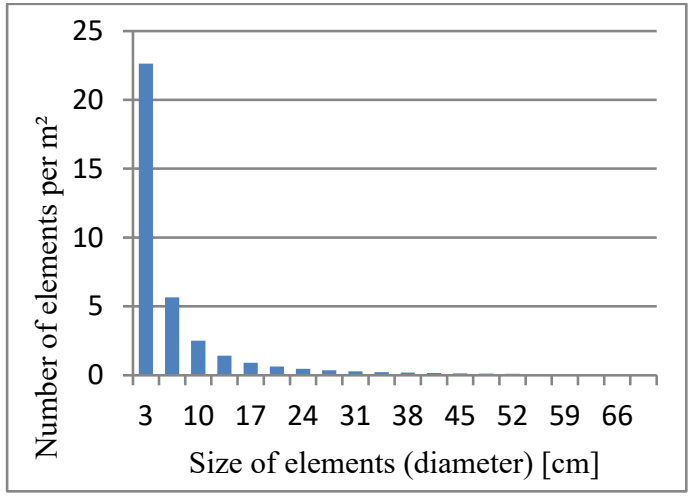

(a)

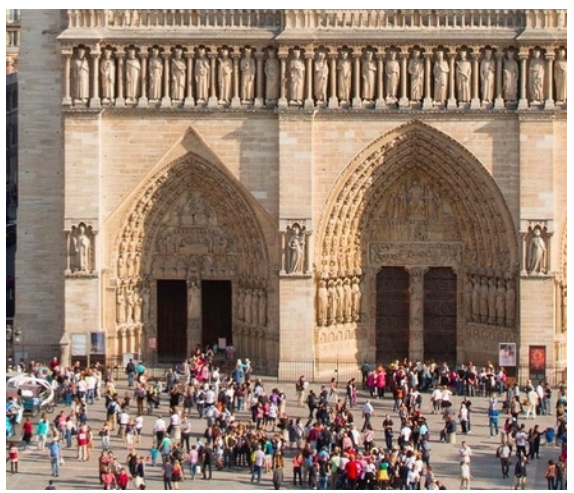

(b)

Figure 18: The characteristic of a fractal façade. A real (partly) fractal behaviour would result in a determined number of elements that increases rapidly with their decreasing size - so smaller the elements so higher their number. (a) The graph shows the mathematical calculation; and (b) The picture shows the portal of Notre Dame in Paris as an example with very high fractal character but of course this is not everyday architecture. (Source: Notre Dame de Paris [19]).

Lorenz [14] states that "On closer observation buildings of the third group (group c) (in Section 5.1 and Fig. 17) consist of a large number of extremely small components that are combined to form a smaller number of larger components and so on, coming up hierarchically to the whole. Fractal geometry then provides the language in which the connection of architectural composition of such different components can be expressed. In a simplified way we could say that fractal geometry helps to describe complex structures." 


\section{FINAL REMARKS}

Fractal design helps the human eye to understand façades and to observe them easily. But fractal is only a precondition for a well-appreciated façade design, there are also other aspects. Fractal design serves only the endeavour of the eye to scan an object, not more but also not less.

This paper shall NOT replace aesthetical design by formulas and simulations; it shall contribute to the discussion of preconditions to reach that target. The secret of aesthetical design is not met by fractal design alone; it is much more. Perhaps it is the smooth variation around the principle of fractal design. Hopefully the secret of aesthetics will never be replaced by formulas and simulations and it will be furthermore a part of the human genius.

A personal comment of the author is given to finish that paper. There is a trend in contemporary architecture to reduce the number of elements and contrasts, to design non-fractal (Fig. 19), all in all not well reflecting the kind of perception by the human eye. It may express the present situation that the surrounding world does not behave like we want to have it and that it is an enemy. A logical consequence seems to be a façade design that is "un-natural," "contemporary".
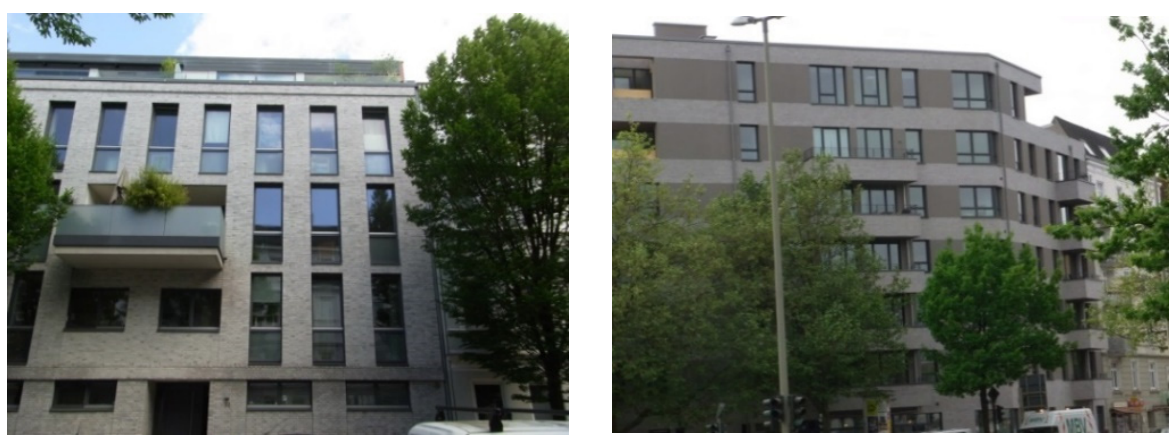

Figure 19: Examples for typical contemporary façades (year of construction: 2017) of apartment buildings in Hamburg. Obviously, it was the will of the planers to design façades with a limited number of elements and a widely non-fractal composition. Further, existing contrasts between elements were still reduced or suppressed (dark frames in dark façade, grey(!) bricks, non-inviting entrance etc.) (all pictures by the author).

Here we are at the crossroads: shall we declare our environment as an enemy, or shall we develop ourselves further to an opinion that we have to live in accordance with our environment? Then, the answer in the design of our buildings should follow (again) that philosophy.

\section{REFERENCES}

[1] Dietrich, U., The impact of the human eye's perception on the walkability of street canyons. WIT Transactions on Ecology and the Environment, vol. 238, WIT Press: Southampton and Boston, pp. 75-86, 2019.

[2] Eye Tracking, Foveal vision. https://eyetracking.ch/wordpress/wp-content/uploads/ 2014/01/Gesichtsfeld-Sehbereich-mit-EyeTracking-in-Usability-Tests.jpg. Accessed on: 22 Dec. 2019.

[3] Hasse, C., Blickbewegungen auf Fassaden, Shaker: Aachen, 2012. 
[4] Hockney, D., Place Furstenberg, Paris, 1985. http://3.bp.blogspot.com/8MTV9ouBBDI/UQeMNhBo_II/AAAAAAAAWE0/WE3n4vdQF4s/s1600/hockney -furstenberg-paris.jpg. Accessed on: 22 Dec. 2019.

[5] Tripadvisor, Attraction review. www.tripadvisor.de/Attraction_Review-g187147d191148-Reviews-Place_Furstenburg-Paris_Ile_de_France.html\#photos;aggregation $\mathrm{Id}=101 \&$ albumid $=101 \& \overline{\text { filter}}=7 \& \mathrm{ff}=32067 \overline{5994}$. Accessed on: 22 Dec. 2019.

[6] Bielefeld University, Augenbewegungen und visuelle Aufmerksamkeit. www.techfak.uni-bielefeld.de/ ihkoesli/vab2011/07-vab2011-hk-augenbewegungensw.pdf. Accessed on: 22 Dec. 2019.

[7] The Vision of Alfred Yarbus, Attention effects. https://yarbus.eu/attention-effects/. Accessed on: 22 Dec. 2019.

[8] Musée d'Orsay, Edouard Manet, “The Balcony”. www.musee-orsay.fr/en/ collections/works-in-focus/search/commentaire_id/le-balcon-7121.html?no_cache= $1 \&$ tx_commentaire_pi $1 \% 5$ Bsword $\% 5 \mathrm{D}=$ manet $\% 20$ balcon\&tx_commentaire_pi $1 \% 5$ BpidLi $\% 5 \mathrm{D}=509 \% 2 \mathrm{C} 842 \% 2 \mathrm{C} 846 \% 2 \mathrm{C} 847 \% 2 \mathrm{C} 848 \% 2 \mathrm{C} 850 \& \mathrm{tx}$ _commentaire_pi $\% 5 \mathrm{Bfrom} \% 5 \mathrm{D}=851 \& \mathrm{cHash}=\mathrm{f3} 1 \mathrm{eb} 673 \mathrm{ab}$. Accessed on: 22 Dec. 2019.

[9] Hamburger Kunsthalle, Paul Klee, "Revolution des Viaductes", 1937. www.hamburger-kunsthalle.de/sammlung-online/paul-klee/revolution-des-viaductes. Accessed on: 22 Dec. 2019.

[10] Salingaros, N.A., Fractal art and architecture reduce physiological stress. Journal of Biourbanism, II(2), pp. 11-28, 2012.

https://journalofbiourbanism.files.wordpress.com/2013/09/jbu-ii-2012-2_nikos-asalingaros.pdf. Accessed on: 22 Dec. 2019.

[11] Imgur. http://i.imgur.com/UjFLY9S.jpg. Accessed on: 22 Dec. 2019.

[12] FanPop. http://images6.fanpop.com/image/photos/36600000/Green-image-green36661177-2500-1875.jpg. Accessed on: 22 Dec. 2019.

[13] 3.bp.blogspot.com. http://3.bp.blogspot.com/-wnlwd qr-cQ/UJNjzy81xCI/ AAAAAAAAGgw/VAKssSKvYFg/s1600/a302_f1.jpg. Accessed on: 22 Dec. 2019.

[14] Lorenz, W.E., Fractal geometry of architecture. Www.researchgate.net/publication/ 30872433_Fractal_Geometry_of_Architecture_Implementation_of the_BoxCounting_Method_in_a_CAD-Software. Accessed on: 22 Dec. 2019.

[15] Taylor, R.P., Reduction of physiological stress using fractal art and architecture. Leonardo, 39(3), pp. 245-251, 2006.

[16] Le Gallerie Degli Uffizi. www.uffizi.it/en/artworks/birth-of-venus. Accessed on: 22 Dec. 2019.

[17] Taylor, R.P., Spehar, B., Van Donkelaar, P. \& Hagerhall, C.M., Perceptual and physiological responses to Jackson Pollock's fractals. Frontiers in Human Neuroscience, 5(60), pp. 1-13, 2011.

[18] R \& B Glass Industries, Toughened glass façade. http://rbglassind.com/images/ products/toughened-glass/toughened-glass-facade/pic01.jpg. Accessed on: 23 Dec. 2019.

[19] Notre Dame de Paris, La façade occidentale. www.notredamedeparis.fr/decouvrir/ architecture/la-facade-occidentale/. Accessed on: 11 Jan. 2020. 